LYNDA BIRKE, "Learning to Speak Horse": The Culture of

"Natural Horsemanship" …………………………………. 217

Carol Freeman, Imaging Extinction: Disclosure and Revision

in Photographs of the Thylacine (Tasmanian tiger) Revion 241

Bradley T. Klontz, Alex Bivens, Deb Leinart, and Ted

KLONTZ, The Effectiveness of Equine-Assisted Experiential

Boria SAX, How Ravens Came to the Tower of London .......... 269

Jacquie E. Lewis, The Significant Life Experiences (SLEs) of

Humane Educators ……………………………………. 285

ISSN 1063-1119

(print version)

(online version)

\section{Review Section}

Wendy Woodward, A Cautionary Tale: The Whale Caller

by Zakes Mda ……………………………………………... 299

Marion W. Copeland, A National Book Award Winner: The

Echo Maker: A Novel by Richard Powers .............................. 301

Kari Weit, The "True" Story of a Misnamed Female Tortoise

Timothy; Or, Notes of an Abject Reptile by Verlyn Klinkenborg. 305

Books Received

309
VOLUME IS

NO $3-2007$

ALSO AVAILABLE ONLINE 
SOCIETY \& ANIMALS

Journal of Human-Animal Studie.

\section{Aims eै Scope}

U Animals publishes studies that describe and analyze our experience of non human ancial. The goal of the journal is to stimulate and support an emerging content area within the
sociesces and the humanities " $H$. human animals figure in our lives.

\section{Managing Editor}

\section{Associate Editors}

(Untiversity of Lancaster, Women's Studies), ERICA Fudge (Middlesex University, UK, Literature), BuLL HENRY (Metropolitan State College of Denver, Psychology), HAROLD
Herzog (Western Carolina, Psychology), CARoL Raupp (California State University, Psychology), Cunt SANDERS (University of Connecticut, Sociology)

\section{Review Editors}

Jonathan Burt (Cambridgeshire Fens, Independent Scholar), Marion Copeland (Holyoke

\section{Board of Editors}

ARnold ARLUKE (Northeastern University, Sociology), STeVE BAKER (Central Lancashire, Socios), Ger. BECK (Purdue, Veterinary Medicine), PIERS Beirne (Southern Maine, erature), CuffTon FiynN (South Carolina, Sociology), Robert GaRnER (Exeter, Political Science), Theresa GobDeke (Horida A\&M, Sociology), Jessica Greanebaum (Central Connecticut State, Sociology), KATHLEEN M. HEDE (South Horida, Criminology), TiM (University of Colorado, Sociology), HuDA Kean (Ruskin College, Oxford, History), SARA KNIGHT (University of Portsmouth, UK, Psychology), GarRy Marvin (Southlands College, Anthropology), Oun Eugene (Gene) MYers, JR. (Western Washington, Psychology), RANDY

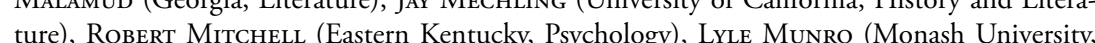
Sociology), HARRIFT Rrtvo (Massachuserts Institute of Technology History), Niger RotuFEIS (Wisconsin, Milwaukee, History), James Serpell (Pennsylvania, Ethology), Tania Signal (Central Queensland, Psychology), ALERRIE KATHRTN SiMS (Central Forida, Ssychology), CHRIS

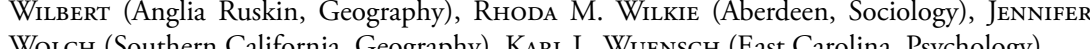

\section{Senior Editor}

Frances H. Albrech

All correspondence should be sent to Society e Animals, Dr Kenneth Shapiro, P.O. Box 1297 , Washington Grove, MD 20880-1297, USA, e-mili: kshapiro@igc, org or kshapiro@animals

Society \& Animals (print ISSN 1063-1119, online ISSN 1568-5306) is published 4 times a year (0)71 5317532 .

\section{Abstracting e Indexing}

Contents, epras ss abstracted/indexed in: Agricola CRIS, Criminal Justice Abstracts, Current Contents, e-psyche, Focus on: Veterinary Science \& Medicine, Int 1 Bibliography of the Socia Sciences Citation Index, Social Services Abstracts. Sociological Abstracts, Wildlife Review bstracts, Zoological Record, IAB

\section{Subscription rates}

or institutional customers, the subscription price for the print edition plus online access of to the online-only version at EUR 185 / USD 234. Individual customers can only subseribe to the print edition at EUR 50 / USD 64. Please check our website at www.brill.nl/soan

All prices are exclusive of VAT (not applicable outside the EU) but inclusive of shipping \& handling. Subscriptions to this journal are accepted for complete volumes only and take effect Claims

Claims for missing issues will be met, free of charge, if made within three months of dispatch for Cons

\section{Online access}

For details on how to gain online access, please refer to the last page of this issue or visit Society Animals online at www.brill.nl/soan

\section{Subscription orders, payments, claims and customer service}

BRILL, clo Turpin Distribution, Stratton Business Park, Pegasus Drive, Biggleswade, Bedfordshire SG18 8TQ, United Kingdom, tel. +44 (0) 1767604954 , fax +44 (0) 1767601640 , e-mail

\section{Back volumes}

Back volumes of the last two years are available from BRILL. Please contact our customer service

For back volumes or issues older than 2 years, please contact Periodicals Service Company (PSC), 11 Main Street, Germantown, NY 12526, U.S.A. E-mail psc@periodicals.com or visit PSC' (1) 2007 by Koninklijke Brill NV, Leiden, The Netherlands Koninklijke Brill NV incorporates the imprints BRILL, Hotei Publishing, IDC Publishers,

All rights reserved. No part of this publication may be reproduced, translated, stored in a retrieval system, or transmitted in any form or by any means, electronic, mechanical, photocopying
recording or otherwise, without prior written permission of the publishers.

Authorization to photocopy items for internal or personal use is granted by the publisher provided that the appropriate fees are paid directly to Copyright Clearance Center, 222 Rosewood Printed in the Netherlands (on acid-free paper)

Visit our web site at www.brill.nl 


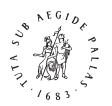

\title{
"Learning to Speak Horse": The Culture of "Natural Horsemanship"
}

\author{
Lynda Birke \\ Honorary Research Fellow, Department of Biological Sciences, Anthrozoology Unit, \\ University of Chester, Parkgate Road, Chester CH1 4BJ, U.K. \\ E-mail: lb.thepublisher@care4free.net
}

Sent 6 November 2006, Accepted 24 January 2007

\begin{abstract}
This paper examines the rise of what is popularly called "natural horsemanship" $(\mathrm{NH})$, as a definitive cultural change within the horse industry. Practitioners are often evangelical about their methods, portraying $\mathrm{NH}$ as a radical departure from traditional methods. In doing so, they create a clear demarcation from the practices and beliefs of the conventional horse-world. Only $\mathrm{NH}$, advocates argue, properly understands the horse. Dissenters, however, contest the benefits to horses as well as the reliance in $\mathrm{NH}$ on disputed concepts of the natural. Advocates, furthermore, sought to rename technologies associated with riding while simultaneously condemning technologies used in conventional training (such as whips). These contested differences create boundaries and enact social inclusion and exclusion, which the paper explores. For horses, the impact of NH is ambiguous: Depending on practitioners, effects could be good or bad. However, for the people involved, $\mathrm{NH}$ presents a radical change-which they see as offering markedly better ways of relating to horses and a more inclusive social milieu.
\end{abstract}

\section{Keywords}

natural horsemanship, riding technologies, communication, social change

\section{Introduction}

...Why keep him tortured, chained and mad/And dungeoned from the daylight's gold? His blood's the best we've ever hadl And all his stock are sound and bold. IMaybe-I crossed the sunlit lanes,/And only saw, with eyes abrim/The torn brown breast, the trebled chains/ The broken heart; and wept for him. (excerpt from "Banshee" by Will H. Ogilvie)

Yes, it is possible-sometimes - to control large nonhuman animals like horses by force: History is full of examples, from mustangs shackled and roped for 
breaking in the old West to the terrible beatings administered to cab horses in the streets of Victorian London. The reasons are usually utilitarian-as the terrified groom in Ogilvie's (1994) poem asserts. But, as good horsepeople have known throughout centuries, you are unlikely to get much cooperation from your horse if you use force- not to mention exposing yourself to considerable danger.

When Sewell (1877/1909) wrote Black Beauty, hers was a rare voice of dissent. Over a century later, people sometimes use force with horses. Just as common, however, are expectations that people try to be kind to animals. Attitudes have changed, not least through the effects of animal rights and environmental politics. In the world of horses and their people, however, some particularly dramatic changes have occurred recently; indeed, there has been something of a "revolution in horsemanship," judging by the tide of new books, websites, and chat rooms dedicated to a rejection of old, harsh, ways of interacting with horses (Miller \& Lamb, 2005). In this new world, it is not enough just to be kind within old established systems of husbandry and training. On the contrary, how we keep horses and how we train them are increasingly challenged.

This drive toward what advocates generally call "natural horsemanship" is a significant shift in the horse-world, both in Europe and in North America, The success of novels like that of Evans (1995) — and the subsequent filmand autobiographies such as Roberts (1997) fuel the shift. The emphasis is on kindness, with particular emphasis on communicating with - and learning to understand from the horse's point of view- the natural behavior of horses. Not surprisingly, a great many horse owners turn to Roberts in the belief that natural horsemanship methods offer something that will give them a closer, more trusting, relationship with their horses.

Yet although much has appeared in the popular equestrian press about the horsemanship "revolution," there has been less academic interest in the horse industry and its participants. ${ }^{2}$ Here, I explore the emergence of natural horsemanship (NH) within the world of caregivers (owners) of leisure horses; that is, among people who own horses for pleasure rather than for participation in the more intensively competitive equestrian worlds. My own involvement has always been as a horse-owner, through Pony Club and, later, in specific, competitive disciplines (especially show jumping). In that sense, my training has been conventional; I am not part of specific constituencies of $\mathrm{NH}$, although I am clearly part of the wider constituency of horse people.

I became interested in the ideas behind $\mathrm{NH}$ as it grew in popularity, partly because it represents a cultural change and partly because of claims $\mathrm{NH}$ practitioners make about horses and what is good for them. My primary purpose, 
then, was to explore this shift, focusing specifically on perceptions of people who self-identified as advocates of natural horsemanship and training:

1. How do they view their changing relationship to their horses?

2. How do they interpret it?

3. What has it changed in terms of training? and

4. How does this relate to the wider horse industry?

\section{What Is "Natural Horsemanship"?}

That there is an art to how humans relate to horses has been acknowledged since the ancient Greeks, when Xenophon published his "Art of Horsemanship." Good classical riding, too, has retained that traditional belief that the relationship and the skills of riding must be firmly based on something called "horsemanship" —an ability to understand what the horse is thinking and feeling and to act accordingly, with sensitivity.

Horsemanship, however, is a very hard-won skill that few can claim. In Britain, organizations such as the British Horse Society and the Pony Club provide frameworks for training and develop standards for horse care, while riding schools providing tuition should be registered. But that framework is no guarantee that horse owners will seek it: Some do, preferring to have recognized training, while others shun such formality, often seeking trainers and methods outside the "system." However good the training, it does not guarantee that "something extra," an indefinable quality described as horsemanship that provides understanding of horses' behavior and what they might do next. That understanding matters, not only for horse well being but also for human safety around such large and potentially dangerous animals.

For most horse owners, management experience often comes from a local riding school or from keeping their horse on a yard with several others. ${ }^{3}$ Some of these may have high standards of horse care; others do not. In addition, many riding schools have large numbers of horses and ponies and even larger numbers of clients, giving personnel little room for giving quality time to individual animals (as several participants in this research complained). In such situations, some owners inevitably feel that something is missing, that horses become part of a production line, or that things simply "could be done better."

Searching for an alternative occurs, moreover, when animal rights are part of a wider cultural agenda, and "the natural" - through diverse choices such as diet and health care-is valorized in popular culture. Television, natural 
history programs, and growing interest in "animal minds" further sharpen a thirst for understanding animals in nature. As several respondents in my research acknowledged, there is little that can be said to be "natural" about the way we keep horses in Britain (they are stabled, bridled, saddled, and given pharmaceuticals). However, there is a desire to understand horses and interact with them in natural ways; that is, draw on what is seen to be the animal's instinctive behavior patterns and on what people perceive as equine behavior in the wild.

According to Miller and Lamb (2005), natural horsemanship—while building on long-established ideas of rapport with horses-really took off after the 1970s. The "revolution" began, they suggest, on American cattle ranches. Despite the stereotypes, cowboys-Miller and Lamb argue — had to be gentle with horses, to see the world through their eyes. Since then, the idea very effectively has been taken up, marketed, sold through educational clinics, and has spread widely in North America and Europe. Given that background, it has been particularly associated with Western styles of riding, although that link - at least in the United Kingdom-is beginning to change.

There are many practitioners with differing styles and points of view advertising as "natural horsemen/women." However, all emphasize understanding why horses do what they do and approaching them with sensitivity. Perhaps one of the best known is Roberts (1997), an American horseman who shot to fame in Britain after being invited by the Queen to give demonstrations of his techniques of "starting" unridden young horses. Others prefer the kind of approach developed by Pat Parelli, a Californian trainer, whose approach to creating more "savvy" horse owners spread rapidly throughout North America and Europe. ${ }^{4}$ In addition to these trainers, who use specific systems that they try to convey to a wider public, there are a number of self-styled "horse whisperers" who claim to be able to help you with your horse's problems by almost supernatural means. ${ }^{5}$

Not surprisingly, there are a myriad of different methods used, while groups of enthusiasts and trainers form and reform, split, and create counter-groups. Some horse owners and trainers resist categorization, preferring to draw on several approaches at once. Others dislike the term natural horsemanship, preferring to use other adjectives (Intelligent horsemanship ${ }^{6}$ ). My focus in this study, however, was not on specific methods and their differences or on their efficacy. Rather, I focused on the horse people interested in NH and their common ground; that is, their rejection of cultural values seen to be associated with mainstream equestrian training and their valorization of methods deemed to accord more with the horse's natural behavior. Again, on common ground, participants spoke about using or rejecting specific techniques or systems 
based on quasi-scientific approaches to horse behavior (emphasizing learning theory or equine behavior in the wild); in that sense, these practitioners differ from some forms of horse whispering based on a kind of mystical communication with horses (or, at least, they say they do).

Using semi-structured interviews, the study is based on qualitative methods. I sought to explore participants' beliefs (and how they create in discourse a new world of $\mathrm{NH}$ ) alongside analysis of written material from natural horsemanship websites and printed materials. That is, the focus was not on what these horse people actually did with their horses but on how they spoke about horses and riding. Interviews were carried out face-to-face and tape-recorded or through iterative email correspondence; transcripts were subsequently coded to identify consistent themes and analyzed using a form of discourse analysis (Potter \& Wetherell, 1987).

Participants were recruited mostly through websites and chat rooms dedicated to various aspects of natural horsemanship, specific training centers, or recommendation from others (snowball sampling). There are several schools of thought in $\mathrm{NH}$-however, many people reported using a "mix-and-match" approach, drawing on various experts' opinions (although 70\% said that they use or had used Parelli or a derivation, at least in part). I did not, therefore, separate particular approaches. Rather, the participants had something in common: They identified themselves taking up $\mathrm{NH}$ as an alternative approach-usually quite recently. After initial analysis, participants were sent a summary of the main themes for further commentary and validation.

I conducted 48 interviews - 14 , face-to-face; the remainder, through email. The sample consisted of 5 men and 43 women, aged 15 to mid-60s. All lived in the United Kingdom. All those who were interviewed face-to-face were Caucasians; questions regarding ethnic or social class background were not asked in the email interviews, which focused solely on experience with horses. Most participants had many years' experience with horses (median 20 years); almost all owned at least one horse. Nearly all owned horses for their own pleasure; the horses were of a wide variety of breeds and types. Four participants ran commercial livery yards or equestrian centers; seven were trainers (drawing on $\mathrm{NH}$ techniques). The considerable gender disparity partly reflects the predominance of women in the horse-world: Women outnumber men in most horse organizations and as horseriders ${ }^{7}$ (with the exception of specific male-dominated spheres such as the horseracing industry). It also reflects a marked disparity in take-up of NH (Burr, 2006; Miller \& Lamb, 2005). ${ }^{8}$

Most of the people I interviewed were $\mathrm{NH}$ enthusiasts, although some were critical; that is, they had learned and used some $\mathrm{NH}$ methods and decided against them. I wanted to ask why people made the shift from long-established 
modes of handling horses to these newer ones and to explore what were the implications for horses, humans, and the relationship between the two. Here, however, my focus is on $\mathrm{NH}$ as an instance of cultural change and on how people involved speak about it.

\section{Themes: Defining Boundaries}

Within these shifting cultures, people define boundaries and redefine themselves. Most people emphasized how they changed as they engaged with these new methods. Participants emphasized not only having experienced personal change—growing in self-confidence—but also how they felt their relationship to their horses was developing.

One particularly striking theme in interviews, in websites, and in chat rooms is the sheer enthusiasm for these new approaches. Even dissenters, who had experienced or observed problems with some methods of $\mathrm{NH}$, remained committed to finding alternatives to what they configured as traditional approaches. In this way, they established an oppositional discourse, roundly rejecting anything they saw as belonging to the conventional world of equestrian culture. Respondents mapped out social boundaries and communities, creating relatively closed worlds of in-and out-groups. Not surprisingly, those who were not part of an in-group were described as failing their horses.

Of course, not all those interviewed were complete converts to specific methods of NH; those who were, however, were full of zeal. Several (N=9) had had some sort of epiphany-a clear moment when they "saw the light" and came to believe that everything that went before was wrong. Harriet, ${ }^{9}$ an owner of a livery yard (looking after other people's horses) described going to see a demonstration of Parelli methods: "It made me cry with awe and I felt thoroughly ashamed of the relationship I had with my horse when I saw what was possible." Similarly, Felicity, who described herself as a novice rider, felt she,

... wanted to BURST out in a blast what [the Parelli method] has done for me and my horse and where it is taking us. There is not a single word to describe it, it's awesome, enlightening, emotional; it's truly exciting and wonderful!

This kind of conversion meant there was "no going back."

Some owners referred to the romance of close relationships with horses. ${ }^{10}$ Part of advanced training in the Parelli system includes work "at liberty" - that is, horses are trained to respond to cues from the person, even while they are not bridled or saddled. This may mean directing the horse over a jump 
while the person stands alongside—similar to how agility dogs learn to jump obstacles. This sense of working with the unrestrained horse evoked similar awe: "To know that your horse is free to move away from you at any time, but doesn't, is one of the nicest feelings in the world," commented Karen, a livery yard manager studying the Parelli program. Sam, an amateur horse owner, spoke of how he could now do things he would never have dreamed possible-circling his horse at liberty or lying on the ground with her head in his lap.

Another owner, Sally, spoke about how she lost heart in the conventional system, which had given her an "emotional block," so she began Parelli: She described how she loved riding with no bridle or halter, which gives her a "really big feeling." Asked to clarify her feelings about liberty work, she commented:

It's the romance, isn't it, I think, the Black Beauty... have you seen the film The Black Stallion? It's that, it's the childhood romance... and it's, so many horses don't want to be with their owners, they bite, they kick ... they do things begrudgingly ... it's just a vicious cycle... this is just the opposite, you ask the horse and he trots toward you.

Alongside enthusiasm is an explicit rejection of traditional methods. Time and time again, respondents spoke about how traditional training had let them down and their horses too. A majority of respondents (70\%) characterized it as being brutal, focusing too much on technique, not taking the horse's point of view, and encouraging a "grab it and go mentality." There were, several felt, negative consequences for the horse: Horse-owner Sandy described how unhappy she had been about the treatment of horses in the riding schools she had attended earlier- the animals were treated as production lines:

I felt that, um, that horses were treated like machines, you weren't actually understanding what was going on with them inside their heads, whether it was a behavioural problem or just not understanding them, there... there... all horses were sort of treated in the same format, like in a sausage factory, they went through treated the same, came out, but they are all different.... and that's what I felt was missing. Some horses went all traumatic in a Riding School but others didn't, that's what I'm saying.

For Sandy, using NH techniques enabled her to work with her horses' individualities and to heal the traumas.

In riding schools, respondents suggested, too many people were prepared to "beat the horse into submission" or to use "push-shove" methods. Students reported being told what to do with their feet and legs but not why they should be doing it in relation to communicating with the horse. They were 
told repeatedly to "kick on" and if they did not get the desired result, perhaps the horse was characterized as naughty, requiring punishment in the form of hitting. Jenny, a manager of a farm and equestrian center, explained,

I think there is a culture, traditionally.... which is quite unpleasant, how hard can you be with your horse? Especially show jumping-you see it all the time.... I used to have a horse that used to bite [someone offered] to beat the crap out of it.

Published literature on NH similarly emphasizes how traditional methods involved a kind of cruelty that is now outmoded (Miller \& Lamb, 2005).

A central tenet of these narratives, then, is clear demarcation from what are seen as conventional approaches: $\mathrm{NH}$ is portrayed as more humane, more fun, better for horses and more inclusive for people. Commenting on this, Sally felt that $\mathrm{NH}$,

\footnotetext{
... does seem to attract more crackpots than usual... they are just extravagant, interesting people, generally alternative people... the general horse-world attracts mostly women, with particular type of horses [such as thoroughbreds, whereas] this world is open to everyone.
}

The conventional equestrian world is—by implication—socially exclusive, as critics opposed to certain equestrian activities on animal rights' grounds have often implied. The anti-hunting organizations in Britain have long pointed to stratification by social class in hunting on horseback.

Yet not everyone interviewed accepted NH enthusiastically. Some criticized specific methods, chose to mix elements of various methods, and suggested that sometimes $\mathrm{NH}$ methods could be just as cruel as many conventional ones. Jan, a trainer interested in animal psychology, explained that, although initially enthused by the apparent kindness of techniques such as "join-up," she now sees it as a, "punitive method not dissimilar to using a choke chain on a dog" and reported seeing $\mathrm{NH}$ trainers hitting horses because the animals spooked at something. Kate, an owner with considerable experience of starting young horses, complained similarly that, in learning Parelli techniques, "My horses were classed as not smart enough... so I had to whack them with my string by going rapidly through the phases [of training]" - an experience she hated and felt her horses did too.

Critics felt that $\mathrm{NH}$ could be as rigid as conventional training, leading to misunderstandings between horse and human. One horse owner, Cath, explained regretfully that, "It has been said that the first horse you take through the program is your sacrificial horse"; horse-trainer Ellie said that in her opinion, all NH methods "desensitize, demoralize, and dominate the animal." She 
went on to explain how, as trainer to both people and horses, she often has to sort out problems caused because both humans and animals are confused. Some of the animals who suffer most, she argued, "... are those whose owner suddenly "has a go" at it. Because it mimics an equine form of "punishment, pet horses suddenly subjected to this can have what I can only describe [as] nervous breakdowns."

With passion running high, it is not surprising that schisms have developed, and several participants referred to splits within particular schools of $\mathrm{NH}$. This in turn generates both a sense of community-some referred explicitly to feeling that they belonged in a community of like-minded people-and of out-groups. One respondent, a trainer, spoke about the "club" feel of some NH. Referring to people using Parelli methods, she said:

When one does Parelli one is very much in the club-and those people who don't... become some kind of enemy - a real out group.... I've heard Pat Parelli say, "look at what your neighbour does and do the opposite...."

She went on to refer to animosity shown by many $\mathrm{NH}$ advocates toward traditional trainers and by many using traditional methods toward those using $\mathrm{NH}$. For many NH enthusiasts, anyone still using traditional methods is failing horses: "I cringe to watch non-Parelli people working their horses," explained Lynn, a horse owner who had discovered the method through a magazine article and taught herself from a DVD.

Schisms aside, there was considerable consensus that $\mathrm{NH}$ was better than traditional approaches and brought considerable change- not only for the horse but also for the human. Nearly all the people identifying as trainers emphasized that they see their job as working with humans, on the grounds that whatever problems the horse/human relationship might have almost certainly originated in equine responses to human behavior. ${ }^{11}$

\section{Changes}

To begin with, people learning NH must change their practices-how they work around horses. Most forms of NH emphasize ground work-working with horses from the ground, teaching them to respond to cues, and asking them to back up or turn sideways — as a precursor to making changes in how the horses are ridden. There are two reasons for this emphasis: one, to encourage owners to communicate better with their horse-learning to speak the horse's language. The second is safety —if they can read equine behavior, then they are less likely to get hurt. 
For some, the predominance of ground work provides a means of interacting with horses without feeling they have to ride. Carrie, who ran a small livery yard, explained how she lost confidence after getting her latest horse. Carrie started the Parelli program,

... because it meant I could work on the ground and didn't have to ride if I didn't feel confident (or could get off if I wasn't happy when riding) — that was a breath of fresh air after the usual traditional 'stay on at all costs' attitude which seemed so prevalent,

Riding thus becomes less a form of physical exercise and more part of a continuum of ways of relating to the horse (Brandt, 2005; Game, 2001), while emphasizing ground work permits playing with the horse: Parelli (1995) made explicit the importance of playing with your horse to earn the horse's cooperation $\left.^{12}\right)$.

Alongside changes in practice, respondents reported changes in attitude toward horses. They felt that the horse's well being was paramount, insisting that humans must learn to "speak horse" and to communicate better. Communication is the key, they argued. However, opinions about what that meant differed considerably. For many, $\mathrm{NH}$ meant that for the first time they felt they were truly communicating. Cassie, a young woman who felt that Parelli techniques worked wonderfully with her family's horses, explained that it offered a method with which "we can all unlock our potential with horses."

This was not only a personal breakthrough but also was better for the horse: It made life more interesting and involved interacting in ways that were intrinsically equine. It was, in Brandt's (2004) words, a "creation of shared meaning." To critics, however, these same methods could lead to confusion and uncertainty for the horse. This was partly because owners sometimes did not take time to learn methods thoroughly and partly, critics insisted, because $\mathrm{NH}$ methods were still based on punishment rather than positive reinforcement, so learning became potentially stressful for the horse. ${ }^{13}$ How horses were seen, then, depended on how people saw training methods; some saw horses with "dull, lifeless eyes" in riding establishments using traditional methods, contrasted to the lively look of horses exposed to NH. Others, however, saw "dull, lifeless eyes" as a result of horses reacting to particular kinds of $\mathrm{NH}$ training.

Yet, although participants reported changing practices, what they felt overwhelmingly was a sense of personal change. Two-thirds explicitly referred to having been through an odyssey. They spoke of how they learned so much about themselves and their personal development and about how they related to other people. Laura, describing herself as a pleasure rider, explained, 
I am learning to be a more controlled person. I don't lose my temper as I used to... you can use Parelli in all walks of your life. I use it as a tool to manage my daughter if she has a tantrum.

Horse-owner Susie, who had attended several NH courses, reported she had,

... learned how to be self-motivated which has helped in other parts of my life, too. It's also helped me become calmer and more focused on things and also more aware of other things/people, so... it's inspired my whole life.

What NH wrought, then, was not only a different way of being with horses; more importantly, it was a different way of being.

\section{"Natural" Technologies}

Owners were generally enthusiastic about doing everything "naturally" with their horses. Given that the focus of interviews was "natural horsemanship," it is hardly surprising that most interviewees used that adjective-but not only to describe kinds of horse training. For many, being natural meant abandoning metal shoes, having horses unrugged in winter, living in herds, having a natural diet, and - in some cases—insisting on using forms of complementary medicine such as homeopathy. These choices are, unsurprisingly, more controversial in mainstream equestrianism. Fifteen interviewees used the word in such non-training contexts, to describe how they kept their horses. Liveryyard owner Karen spoke about how she preferred her own horse to be unshod and unrugged, even in winter/

I love the fact that I'm not nailing shoes onto her beautiful hooves.... I feel she can regulate her temperature herself if I don't disturb her in any way. As far as I'm concerned, the more natural the better!

Others use the term to describe the method of training they were following. As Cassie explained,

The method itself is superb because it is natural. Nature itself is a perfect system. However, you have to learn to become natural in what you do... they are cared for naturally by the human, and this is always beneficial because horses evolved to live naturally.

Yet while many were happy to use naturalness to describe a kind of utopian ideal for their horse and the way the horse is kept ("I want him to be as 
natural as possible"), several respondents questioned it, on the grounds that domesticated horses are not natural, nor are the ways humans relate to them. "We are not going bareback, bridleless in Arizona plains," noted Carrie.

Others contested notions of naturalness in relation to specific practices such as "barefoot trimming" - not using metal shoes, sometimes with the owner learning techniques of foot trimming. This practice, though enthusiastically endorsed by some interviewees, has been condemned by many in the horseworld (especially if carried out by owners with little or no training in farriery) and was the subject of litigation in Britain in 2006 on grounds of causing a pony considerable pain. Similarly, not using rugs was also disputed. Kate explained how she had been repeatedly mocked for using rugs on her thoroughbred horses who, she believed, preferred to come into the stables for a feed. She had,

... seen some very poorly kept horses in NH circles. Thoroughbreds kept outside all winter, no rugs, hardly any hard feed, because that is the natural way to do it! However, nature did not design thoroughbred horses, nor their Arab ancestors, to live in our climate.

Some respondents were noticeably hesitant when talking about how they kept their horses, especially if they were doing something disapproved of within NH circles. Kelly, a student of the Parelli method, was explaining how she keeps her horse out at grass as much as possible; but, she acknowledged, her horse is,

... very protective of "his" grass; so, umm, he became dominant, so I... [hesitation] er, keep them separated [hesitation] with, ummm, electric fencing.

Up to that point, her oral narrative had been clear and articulate, but suddenly her style changed: her hesitations became defenses against implied criticism. What counts as "good for horses" is highly contestable terrain, influenced at least partly by cultural beliefs. ${ }^{14}$

It is, perhaps, in relation to associated technologies—gadgets—-that naturalness is most disputed. Mostly, using gadgets (whips, spurs, particular kinds of bit) was attributed to conventionally trained riders, or perhaps to riders in specific disciplines (such as show jumping) and was usually associated with misuse. Dee, an owner who competed competitively in carriage-driving, explained how she linked overuse of gadgets to humans' role as predators:

My reasoning being the human race is set on 'Order and Command'. For many years people have rode (sic) horses and enforced them to do as they wanted.... If a horse 
reacted negatively because of discomfort or pain they were met with harsh gadgets, whips and spurs.

By contrast, many interviewees spoke of how NH trainers discourage the use of such gadgets; rather, riders are taught to find other ways to encourage their horse to go forward/slow down, through better riding techniques. As Lou, another amateur horse owner, acknowledged, there is, a climate of hostility toward gadgets in $\mathrm{NH}$ :

On the chatboard, the majority of people are very anti-whip and spurs. However, my horse takes the $\mathrm{P}^{* *}$ s if I am not wearing spurs. She seems to know that I've not got them on and so misbehaves.

Yet several NH approaches use other technologies (or similar ones given a different name)—what differs, however, is the interpretation. Given that advocates speak about NH methods as kinder, gentler, and more natural, they inevitably see their use of gadgets accordingly. But critics interpret these gadgets differently: Kate, recounting her criticisms of several methods of NH, commented on the use of aids like the "carrot stick" in the Parelli method (a long stick used to touch or tap the horse), which she had observed being used to hit:

I do not believe for one moment that smacking a horse around the head with a carrot stick to get their attention is any more natural than people riding around in 3-ring gags [a type of bit, which can be more or less severe, depending on where the reins are attached].

Ellie described in detail how she, in her role as an instructor, had seen a number of abuses in the name of NH. She had seen a young mare tied overnight to a post by an $\mathrm{NH}$ instructor and left to accustom her to the pressure halter-not a gentle use of the device, she felt. She went on to criticize how people come to relabel gadgets (such as the carrot stick), describing a client of hers who asked, "what her rope was called.... it's got special ends!" On being told that the rope was just an ordinary one that was frayed, the other person asked where she could buy one. To this critical trainer, a carrot stick is just a whip if it is used to hit_ "hitting a horse with a stick is hitting a horse with a stick regardless of what it is called," she argued.

So, although most $\mathrm{NH}$ advocates abhor use of gadgets, what they mean by this are technologies long-employed in traditional equestrianism-whips, spurs, and particular forms of bits-rather than technologies used routinely in NH. It is, moreover, not only misuse of such devices-sharp digs with 
spurs - but their use at all that is abhorred. Those who continue using them in the face of that opposition must find justifications - "my horse takes advantage." Yet it is not gadgets per se that are seen as the problem-only those deemed bad for the horse's welfare (through hitting or pulling on the horse's mouth). In contrast, some schools of thought within NH encourage the use of specific gadgets: long lines, carrot sticks, and round pens. These are accepted because they are used in a "different way" - to extend a human arm or to limit the horse's movement. To outsiders, many of these devices might look quite similar to devices used by traditional riders/trainers; within $\mathrm{NH}$, these gadgets acquire different names, and (crucially) their action is reinscribed. Thus Cassie explained that her "horse was not afraid of me when I didn't have the carrot stick on me (one of the tools we use, extension of your arm, NOT A WHIP in any way)". Clearly, she knew that others might see a whip where she sees a carrot stick, and she felt it important to explain the difference. It is precisely this reinscription of meaning that critics contest.

Technologies of control have long been part of the world of traditional horse people. Although some of these are indeed quite drastic (strong bits used on strong horses), many people in this world seek to find the best control by milder means. Yet these technologies can be, and often are, used as forms of punishment. Most competition riders can tell tales of "what can be seen behind the horse lines" when riders are frustrated by their horse's performance. So, in a newly emerging culture emphasizing kindness to the horse, technologies of control—of whatever form — become potentially problematic: Like all such technologies, they can be abused. One response to that dilemma is to reinscribe meaning.

\section{Cultural Change}

There are many different communities within the horse-world, each with its own constituencies, sets of rules, and customs - the racing industry (Cassidy, 2002), polo, dressage, jumping, eventing, hunter/jumping (Brandt, 2004). However, it is not, on the whole, within these worlds that $\mathrm{NH}$ is making its biggest inroads but in the world of leisure horses-owners with one or two animals, kept for pleasure rather than competition.

Horsemanship in earlier centuries was linked with war and the aristocracy; the methods of controlling horses were generally punitive. By the eighteenth century, however, there was more emphasis on making horses self-regulating and less emphasis on cruel punishments (Mason, 2000). Linked to these shifts in training, Mason argues, were changes in recreational riding in England to 
serve more middle-class interests, so that riding cross-country (including riding to hounds in the hunt) largely supplanted the manège as the locus of fine horsemanship. That historical shift has meant that, in Britain, whether or not one supports hunting, it is inextricably linked to mainstream horsey activities.

Within horse cultures, $\mathrm{NH}$ constitutes a significant cultural shift, partly because it is constituted so firmly against what are seen as traditional ways of working with horses and partly because of parallels and links to other cultural changes within the wider society. As I have noted,

traditional ways" are seen by $\mathrm{NH}$ advocates to involve a lack of caring, even cruelty, treating horses and people like a production line. Felicity did not feel that traditional owners had enough respect for their horses; rather, they "treat their horses like cars. Gas them up, take them out for a drive, put them back in the garage and hope they never break down.

That may well be the experience of many riders or horse owners: They typically keep their horses on a small scale, a kind of craft labor. In a largely fragmented industry like the horse- world, advice is usually obtained through loose networks; for people who, say, have a problem with their horse, the question of to whom and where to turn for help is a considerable one. If you ask for instruction at a riding school, you must turn up at a busy yard at an allocated time, get on your horse, and have your lesson. If you are there on your own horse, the instructor may ask you what problems you have; if you don't have a horse, you might be put into a group lesson on a horse you may not know. You will be required to get straight on; during the lesson, the instructor will probably shout out instructions to improve your technique. Like my respondents, I have seen this pattern thousands of times. The horses, as subjective beings, fade into the background of a scene organized around techniques and spaces determined by patterns of human work (stables, arenas, and mechanical horse-walkers). ${ }^{15}$ It is not really surprising if horses are sometimes treated with less than respect.

The belief that horses are treated badly in such systems is the main reason stated for rejecting traditional methods. $\mathrm{NH}$ advocates perceive the newer methods not only as better for horses but also as better for the people involved. Several spoke about the limitations of how people teach in the conventional world: There was not, they felt, enough recognition of how people (or horses) learn. Sarah, a trainer using NH techniques, described how she went to a (non-NH) trainers' convention and observed that none of the trainers were able to suggest how the riders they were watching could improve. Rather, everything was negative: 
...the whole bunch of people, they kept coming up with so much stuff that people had done wrong, they didn't come up with anything that they had done right.... I didn't want to be there, and I didn't say anything....

Carrie, similarly, felt that most of "the instructors I came across did not seem to understand the basic principles of how people learn, how to differentiate, how to help the individual make progress themselves". In contrast, NH was portrayed as epitomizing care for individual horses and riders, as well as being empowering. Whatever else is represented by the rise of popularity in $\mathrm{NH}$, there is also an indictment of some of the training offered through conventional routes.

There is clearly an oppositional discourse in how NH advocates speak. In particular, the narratives offered about NH position the speaker as "kind" and "being in relation to the horse"; at least partly, this positioning could be said to perform kindness in the social situation of the interview. It also sets up an opposition, not only to those who have not yet seen the light but also to what went before: "I thought I knew about horses, but now realize I didn't." Of course, creating oppositional discourses occurs in many social situations; in situations involving animal use, however, the opposition centers on a moral demarcation: Michael and Birke (1994) discuss scientists' moral positioning in relation to their use of laboratory animals. Here, the discourse of kindness and ability to "read horse" serves to create an ethical boundary between those involved in $\mathrm{NH}$ and those who have not yet been converted. No matter how kind to horses are people working in conventional ways, the $\mathrm{NH}$ discourses invariably position them outside.

This boundary-making in turn enacts processes of social inclusion and exclusion, as one respondent explicitly pointed out. The traditional horseworld is perceived as highly stratified and exclusive; in contrast, the NH world is constructed as "open to everyone"-while, to critics, it itself recreates a "club" feel of exclusivity. Yet, however different, the horse is pivotal to social relationships in both worlds; in a study of horses and the ordering of social relationships in what she calls the "New Countryside" in Britain, Latimer (n.d.) notes how attachments to horses help to accomplish social order, as rural social lives can often revolve around horsey activities. Describing a meet of the mounted hunt, she argues that the meet forms a set of "practical activities that performs a sense of a solid community, of a people who know how to handle themselves and nature, who know their place in a prefigured order of things."

For most of the people I interviewed, it is precisely that prefigured order that they do not feel part of, so that $\mathrm{NH}$ does indeed provide them with something that was sorely missing from their experience of traditional horsey 
culture. Indeed, while attachments to horses may be important within the conventional world, they are not necessarily made explicit; by contrast, respondents in this study emphasized the role of the horse and their relationship to it - a role that seemed to them to be much more transparent in the world of $\mathrm{NH}$. In their eyes, $\mathrm{NH}$ offered a new community, within which their relationships with their horses were prioritized. The dramatic change in their relationships after discovering $\mathrm{NH}$ was, to many of my respondents, a revelation, if not a revolution.

The revelation focused on learning to become "partners" with their horses, on "speaking horse." Given that I asked specifically about NH, I would expect people to tell a partnership narrative to me as researcher. Partnership is, after all, a central part of the discourse of $\mathrm{NH}$. However, it has long been part of the discourse of classical riding (Podhajsky, 1987), and good horse persons have long recognized the need to "think from a horse's point of view" (Blake, 1975) - even if this is not discerned by everyone. The problem here is not so much the kind of riding but the body language of the communities associated with it. To those who do not feel part of the world of what Latimer (n.d.) calls Anglo-Irish horsey culture in Britain (with an emphasis on competitions, hunting, and joining the Pony Club), partnership with the horse in that world is invisible; what they see instead is a social exclusivity built on using the horse.

What there is in the $\mathrm{NH}$ interviews, however, is a yearning, a longing for a romanticized ideal of horse/human union and partnership, a longing that seems to drop out of many technical books and courses in the conventional horse-world. Most horsey people acknowledge that longing, but it does not become formally recognized in training, which continues to focus on riding and husbandry techniques and generally adopts a rather rationalist stance. It is, then, not surprising that people speak of finding succor in the newer approaches that make explicit the yearning.

There is, then, noticeable cultural change, at least within parts of the horsey community: However, is it, as has been said, a revolution? Miller and Lamb (2005) acknowledge that these ideas are not really new, as did several of my respondents. In addition, there is certainly resistance among conventionally trained riders both in Britain and in the United States (particularly in the eastern states (K. Brandt, personal communication). What make it different now are information and publicity: Information is easily disseminated through the internet, which also enables leading $\mathrm{NH}$ practitioners to sell themselves (and their products, such as special halters). There is, as cynical critics pointed out in interviews, much money to be made from selling dreams of relationship. 
That learning to communicate with a big, powerful, animal can both transform the person and stand as a metaphor for communication is increasingly used lucratively in other contexts. Roberts (1997) offers training sessions for corporate management: Participants watch demonstrations of horse handling in a round pen and see that as a metaphor for how to manage staff. "More can be accomplished with mutual respect and cooperation than can be accomplished with dominance and aggression," his website suggests - even to the point, it has been claimed, that one major international corporation turned its financial fortunes around after taking on his ideas ${ }^{16}$ There is a parallel in how corporate management has drawn on cultural changes in public understanding of bodily function. That is, corporations increasingly adopted concepts of flexibility that drew on popular understandings of how immune systems work (Martin, 1994); as the idea of bodily flexibility gained currency, so did the idea within management.. Here, too, is a contrast between what is construed as earlier, aggressive methods and newer, gentler ones.

Although several NH instructors were at pains to talk to me about shared goals and methods and how classical training was based on similar precepts, many of the owners who had become $\mathrm{NH}$ users were much more polarized. However, not only do they reject the mores of what they see as a socially exclusive traditional culture but also they turn to specific experts outside it. Unlike most trainers working within the mainstream, many of these new experts take on the status of gurus, almost becoming household names (and indeed marketed as such).

As Brandt (2005) has observed, the origins of most NH in Western riding mean that the figure of the cowboy becomes iconic. Although inevitably there are differences when that Western iconography is transported to Europe, the image of the cowboy remains central. It is, of course, a gendered and racialized image-most $\mathrm{NH}$ experts are male and white; most $\mathrm{NH}$ users are female (Brandt) —and an "alternative" one, bringing with it a romance of deep communion with horses and of the wide open plains. Although this figure is very much part of the imagery of Western riding, he has not been part of the mainstream world of horses in Britain. The top hat, not the Stetson, better characterizes the world of English horses. In that sense, at least, there is a dramatic change associated with $\mathrm{NH}$ : It is peopled and represented quite differently here in the United Kingdom ${ }^{17}$ That in turn can limit the message; critics sometimes complain that certain forms of $\mathrm{NH}$ are simply "too American"not only in style but also in their packaging and commercialization.

The alternative rhetoric used by $\mathrm{NH}$ advocates has much in common with some of the new social movements-the environment, complementary health, and animal rights. These draw on a romantic view of nature, coupled with a 
strong anti-instrumentalism. Writing about the animal rights movement, Jasper and Nelkin (1992) emphasize the rise of protests linked to opposition to modernism and, particularly, to science and technology. It is precisely what is seen as the instrumentalism of science (such as how animals are used in laboratories) that is seen as problematic-overly rational, devoid of feeling, and abusive. That, they suggest, in turn feeds into deeply felt resistance, evident in many contemporary counter-cultures.

There are parallels with $\mathrm{NH}$ here, in that $\mathrm{NH}$ too draws on romanticized notions of nature and the natural and rejects the instrumentalism associated, in the minds of advocates, with traditional horse-training establishments. Unlike, say, the wider animal rights movement, however, $\mathrm{NH}$ is more a cultural change than an overtly political one-it is not obviously associated with public protest. ${ }^{18}$ In that sense, it has more in common with the use of complementary medicine. Sharma (1996) looks at the popularity of complementary medicine in terms of an emerging counter-system, "dialectically opposed to orthodox medicine with its medical scientific paradigm and stress on hierarchical relations" (p. 249). However, she continues, rather than simply see complementary medicine as just another counter-system, it can also be viewed as another set of concerns about individualism and the body-concerns that also have a long history in orthodox medicine. Analogously, we might see the turn to $\mathrm{NH}$ as a resistance to what advocates see as a loss of individualityeither for themselves or for their horses - in many conventional riding establishments. There may be, within the traditional world, a long-standing and deep-rooted emphasis on individuality (at least for the people, who seem to pride themselves on their social eccentricities), but these $\mathrm{NH}$ advocates did not seem to see that. Rather, they saw a uniform, unquestioning acceptance of whatever people had previously been taught-however bad for the horse. What they sought was an individuality; doing $\mathrm{NH}$, they said repeatedly, was different-a journey of discovery and an empowerment for both them and their horses.

\section{Conclusions}

There is undoubtedly a cultural shift within equestrianism that foregrounds how people relate to their horses. That cultural change is represented in how new communities of "horse people" emerge, how new social orders are accomplished, and how different (and oppositional) discourses are created and meanings reinscribed - as well as in terms of how the new methods are commercially marketed. However, it is also a shift that draws on currents long present in 
how people think about horses—-horse whispering did not begin with particular novels or films any more than did the art of horseman/womanship. As Ogilvie's (1994) poem attests, there have long been voices of dissent at methods using cruelty. In that sense, it is hardly a revolution. It is, however, a significant cultural change, which calls into question many established practices in the world of horse/human relationships. Many of these should, indeed, be questioned rather than taken for granted, and there is certainly a message in the world of $\mathrm{NH}$ practitioners about how horses are portrayed and treated and about how people are taught in the well-established, traditional riding schools. On the other hand, there is considerable fragmentation in the world of $\mathrm{NH}$ - a plethora of different people marketing different methods—which may not always bode well for horses.

Some see many $\mathrm{NH}$ practices as good for horses' well being; others criticize them because owners, adopting a piecemeal approach, end up confusing their animals. No doubt many questions can, and should, be asked about how $\mathrm{NH}$ affects people and their horses for good or ill. The growth of NH forces the horse's well being and relationship with humans into the spotlight: Whatever methods we use should take into account the horse's point of view. There is, certainly, a strong strand of instrumentalism in the horse-world, related to the monetary value of horses_- "his blood's the best we've ever had" as Ogilvie's (1994) narrator said of the abused horse in the poem, so that producing progeny mattered far more than the stallion's suffering. Large numbers of horses are slaughtered because that monetary value is not realized. Yet there are many for whom the horse is a friend who should be treated with respect and kindness. These are people deeply opposed to the kind of instrumentality and brutality that Ogilvie captures and that still occur. Whatever criticisms have been levied against different forms of $\mathrm{NH}$ and their practitioners, that emphasis on respect and kindness is an important one. It may be hard to stop institutionalized cruelties, but ordinary horse owners want to find ways of working with horses based on respect-for both the human and the horse. If that is the main message of this cultural change, it should be heard.

\section{Acknowledgments}

I am indebted to all the people who so kindly took the time to correspond with me by email or to speak with me at length about their beloved horses. I am also indebted to Dave Stuart for discussion about various forms of horse$\mathrm{man} /$ womanship and their popularity and for help in contacting some of his students on Equine Ethology courses. I am also grateful to Keri Brandt, Joanna 
Latimer, Mike Michael, and Consuelo Rivera for comments on the paper (and ongoing discussion).

\section{Notes}

1. This is a particularly sexist term, given that the majority of riders are women, and there is a significant majority of women in "natural horsemanship". There is a wealth of feminist questions that could be asked about this (Brandt, 2005; Burr, 2006). However, it is not my remit here; because this term is so widely used, I have kept it, though my abbreviation should perhaps better be read as "horsewomanship" given the preponderance of women.

2. Noteworthy exceptions are Cassidy's (2002) study of the thoroughbred racing industry in Newmarket, England; Brandt's (2004, 2005) symbolic interactionist analysis of human/horse interaction, and Game's (2001).phenomenonological analysis of the act of riding.

3. Many horse owners in Britain keep their horses on do-it-yourself livery yards, where they pay the owner for basic accommodation, which may or may not include grazing. These are sometimes within a barn (a system more common in the United States, where winters can be more severe); sometimes in conventional stables set around a courtyard; sometime in buildings. The standards of these yards vary considerably. They are also a source of information; people often turn for advice to other livery owners, even if they are not particularly experienced.

4. Monty Roberts has extensively used a round pen-a large round corral - to demonstrate "join up." That is, the human must act in ways to encourage the horse to want to come toward the human; this is done initially by chasing the horse away until ithe horse decides to approach. Pat Parelli developed the idea of playing "Seven Games" on the ground with your horse, to ensure that the horse learns to respect what the human wants; the horse must learn to yield to pressure from the hand.. Developing these interactional skills on the ground, argues Parelli, should be fun but should also teach the horse to respect the human. A broadly similar approach is taken in Britain by the Equine Ethology Centre, although this has now separated from the original Parelli franchise.

5. Randle (2006) has noted that the claims made by such people can sometimes be absurd. Randle tells owners that the horse prefers a pink headcollar or, in the case of a newly deceased horse, that the horse "committed suicide for you." Most practitioners of NH as forms of training, however, would distance themselves from such chicanery. Randle distinguishes horse whisperers from horse behaviorists, pointing out that "horse whisperers" who use occult or mystical talk can pose dangers to the horses' welfare.

6. Contributors to the Intelligent Horsemanship website sometimes reject the idea that what we do with horses can ever be natural because, by definition, we are asking horses to do something alien to them. I continue to use the phrase Natural Horsemanship, however, as a kind of generic term, as it is now used by so many.

7. According to a poll of participants on the Voices for Horses website, of people answering questions as clients/horse owners, $12 \%$ were male; among those identifying as professionals (horse trainers), $23 \%$ were male. ( [accessed July 2006]). Where gender is specified, contributors to horsemanship websites are overwhelmingly female (I found approximately $95 \%$ female contributors on one such website). Data from the British Household Survey on behalf of UK Sport indicate that two-thirds of people saying that they had recently ridden a horse were women The Participation of Women in Sport: Report for Sport England; accessed October 2006 from website www.stats4schools.gov.uk. Miller and Lamb (2005) suggest the predominance of women in $\mathrm{NH}$ is partly because "women are nurturing by nature" (p. 81). They also note that the leading 
names of the "revolution" are, however, men, which they explain by suggesting that women are more likely to have problems because horses feel dominant to them.

8. Most people who were approached agreed to answer the questions; the gender disparity was, however, the same among those who did not return the emailed questions.

9. All names used in this paper are pseudonyms.

10. There is a certain irony here in that, while they spoke of the dream of liberty, the horses are still expected to do the usual things, at humans' behest.

11. A similar emphasis can be found in websites advertising new methods of dog training.

12. For further information on Parelli's "Seven Games" see the website at

13. Although punishment is undoubtedly used, negative reinforcement is far more common. The two are, however, often confused. Hockenhull (2006) and McLean (2005) consider the role of different training methods in equine learning.

14. Similarly, Haraway (2003) explores the contested terrain around our relationship with dogs.

15. Gupta (2006) notes how, $\mathrm{n}$ texts focusing on foxhunting, the use of the pronoun "who" is used far more often in relation to the fox, than it is to the horse- the latter is more often referred to as "it" (see note 1 , above).

16. According to Marsh (1998), Volkswagen in the United States turned itself around after adopting Roberts' philosophy (;

17. K. Brandt (personal communication) suggests that, the primary source of popularity for $\mathrm{NH}$ in the United States (at least in the western states) is the cowboy, whereas in the United Kingdom, it seems to be the alleged naturalness of the techniques.

18. Although, as Goldner (2004) notes with respect to complementary therapies, consumption is itself a form of activism: by analogy, consumption in the form of attending $\mathrm{NH}$ clinics and buying specific gadgets could also be activism.

\section{References}

Blake, H. (1975). Talking with horses: A study of communication between man and horse. London: Souvenir Press.

Brandt, K. (2004). A language of their own: An interactionist approach to human-horse communication. Society \& Animals, 4, 299-316.

Brandt, K. J. (2005). Intelligent bodies: Women's embodiment and subjectivity in the human-horse communication process. Boulder: University of Colorado.

Burr, S. (2006). Dancing with horse whisperers: What horse(wo)men want. Poster presented at Proceedings of the 2nd International Equitation Science Symposium, Milan, Italy.

Cassidy, R. (2002). The sport of kings: Kinship, class and thoroughbred breeding in Newmarket. Cambridge: Cambridge University Press.

Evans, N. (1995). The horse whisperer. London: Bantam Press.

Game, A. (2001). Riding: Embodying the centaur. Body and Society, 7, 1-12.

Goldner, M. ( 2004). Consumption as activism: An examination of CAM as part of the consumer movement in health. In P. Tovey, G. Easthope, \& J. Adams (Eds.), The mainstreaming of complementary and alternative medicine (pp. 11-24). London: Routledge.

Gupta, A. F. (2006). Foxes, hounds and horses: WHO or which? Society \& Animals, 14, 107-128. Haraway, D., (2003). The companion species manifesto: Dogs, people and significant otherness. Chicago: Prickly Paradigm Press.

Hockenhull, J. (2006). Does punishment work? Rider responses and behaviour problems in ridden horses. Paper presented at Proceedings of the 2nd International Equitation Science Symposium, Milan, Italy. 
Jasper, J., \& Nelkin, D. (1992). The animal rights crusade, New York: The Free Press.

Latimer, J. (n.d.) Scaling materials: Extension, stratification and horsey worlds. Unpublished paper.

Marsh, A., (1998). The man who listens to horses. Accessed May 5, 1998 at http: [***URL to be added*** please supply***]

Martin, E., (1994). Flexible bodies: Tracking immunity in American culture from the days of polio to the age of AIDS. Boston: Beacon Press.

Mason, J. (2000). Animal bodies: Corporeality, class and subject formation in the wide, wide world. Nineteenth Century Literature, 54, 503-533.

McLean, A. (2005). The positive aspects of correct negative reinforcement. Anthrozoös, 18, 245-254.

Michael, M., \& Birke, L. (1994). Accounting for animal experiments: Identity and disreputable 'others'. Science, Technology and Human Values, 19, 189-204.

Miller, R. M., \& Lamb, R. (2005). The revolution in horsemanship and what it means to mankind, Guildford, CT: The Lyons Press.

Ogilvie, W. H. (1994). Banshee. In O.Way (Ed.), The poetry of horses (pp. 110, 111). London: J. A. Allen.

Parelli, P. (1995). The seven games of Parelli natural horsemanship. [CD-Rom].

Podhajsky, A. (1987). My horses, my teachers. Elverson, PA: Bright Books.

Potter, J., \& Wetherell, M. (1987). Discourse and social psychology. London: SAGE.

Randle, H. (2006). Horse whisperers and horse 'behaviourists': Are we jeopardising our horses? Paper presented at Proceedings of the 2nd International Equitation Science Symposium, Milan, Italy.

Roberts, M. (1997). The man who listens to horses. London: Arrow Books.

Sewell, A. (1877/1909). Black beauty: The autobiography of a horse. New York: A. L. Burt Company.

Sharma, U. (1996). Using complementary therapies: A challenge to orthodox medicine? In S. J. Williams \& M. Calnan (Eds), Modern medicine: Lay perspectives and experiences (pp. 230255). London: UCL Press. 
